\title{
Crust and upper mantle resistivity structure in the southwestern end of the Kuril Arc as revealed by the joint analysis of conventional MT and network MT data
}

\author{
Hideyuki Satoh ${ }^{1 *}$, Yasunori Nishida ${ }^{1}$, Yasuo Ogawa ${ }^{2 * *}$, Masamitsu Takada ${ }^{3}$, and Makoto Uyeshima ${ }^{4}$ \\ ${ }^{1}$ Division of Earth and Planetary Sciences, Graduate School of Science, Hokkaido University, Sapporo 060-0810, Japan \\ ${ }^{2}$ Geological Survey of Japan, Tsukuba, Ibaraki 305-8567, Japan \\ ${ }^{3}$ Institute of Seismology and Volcanology, Graduate School of Science, Hokkaido University, Sapporo 060-0810, Japan \\ ${ }^{4}$ Earthquake Research Institute, University of Tokyo, Bunkyo-ku, Tokyo 113-0032, Japan
}

(Received April 25, 2000; Revised July 5, 2001; Accepted July 5, 2001)

\begin{abstract}
A joint analysis of data obtained by conventional magnetotellurics and network magnetotellurics (band-width, $0.003-7,680 \mathrm{sec}$ ) revealed detailed resistivity structure from the shallow crust to the upper mantle in the eastern part of Hokkaido, Japan, situated in the southwestern end of the Kuril Arc. The results are summarized as follows: (1) A conductive layer (a few to $10 \Omega \mathrm{m}$ ), having a basin structure, is distributed widely to a maximum depth of about $6 \mathrm{~km}$ in the upper crust. Considering other independent studies, such as seismic reflection, gravity and drill core analyses, the bottom of this layer coincides with the boundary between the Tertiary and the Cretaceous formations. (2) A conductive layer (10-40 $\Omega \mathrm{m})$ situated in the lower crust extends from the volcanic front toward the backarc side, and is similar to feature with the Northeastern Japan Arc. (3) A highly resistive layer (5,000-10,000 $\Omega \mathrm{m})$ is analyzed in the upper to middle crust of the forearc side. Since the distribution of this layer is consistent with the high positive gravity anomaly region ( $227 \mathrm{mgal}$ in maximum), the causative material may be common. A collisional tectonic event between the Eurasia plate and the Okhotsk Paleoland in the Cretaceous period may possibly be related with the existence of the layer, although the detailed tectonic implications are left to be solved. (4) The resistivity of the upper mantle is $40-100 \Omega \mathrm{m}$. (5) The resistivity of the Pacific plate is estimated as $700-1,000 \Omega \mathrm{m}$, which is almost consistent with that of the Northeastern Japan Arc $(500 \Omega \mathrm{m})$.
\end{abstract}

\section{Introduction}

Recent advances in magnetotelluric (MT) soundings have revealed the detailed electrical resistivity structure beneath the Japanese Islands, following geomagnetic depth soundings (GDS) in the 1960's-1970's (e.g., Sasai, 1967; Kato et al., 1971; Rikitake and Honkura, 1973; Honkura, 1974; Miyakoshi, 1979; Nishida, 1982). For example, Ogawa (1987) deployed many MT stations and found a conductive lower crust beneath the Northeastern (NE) Japan Arc. Utada et al. (1996) also found a conductive lower crust and a thin conductive layer (10 $\Omega \mathrm{m}$ or so) on top of the subducting Pacific plate in NE-Japan by a combined analysis of MT and GDS data. Succeeding attempts were made by Shiozaki (1993), Fuji-ta et al. (1997) and Yamaguchi et al. (1999) in the Southwestern (SW) Japan Arc which belongs to the subduction zone of the Philippine Sea plate. A conductive layer $(75 \Omega \mathrm{m})$ is also detected on the top of the resistive Philippine Sea plate (Yamaguchi et al., 1999).

Hokkaido is situated at the junction connecting the NE Japan Arc and the Kuril Arc (Fig. 1). Reconstruction of pa-

\footnotetext{
*Now at: Institute of Seismology and Volcanology, Graduate School of Science, Hokkaido University, Sapporo 060-0810, Japan.

** Now at: Volcanic Fluid Research Center, Tokyo Institute of Technology, Tokyo 152-8551, Japan.

Copy right (c) The Society of Geomagnetism and Earth, Planetary and Space Sciences (SGEPSS); The Seismological Society of Japan; The Volcanological Society of Japan; The Geodetic Society of Japan; The Japanese Society for Planetary Sciences.
}

leogeologic history in Hokkaido has been developed since the early 1980's (e.g., Kiminami et al., 1986) from plate tectonics theory based on much geological evidence. Hokkaido is believed to have formed through two stages of major collisions between land masses. One of these occurred between the Eurasia Plate and the Okhotsk Paleoland in the late Cretaceous or Paleogene (e.g., Niida and Kito, 1986; Sakakibara et al., 1986). The other between the Kuril forearc and the NE Japan forearc in the late Miocene (e.g., Kimura, 1981, 1986). In addition to such past tectonic events, subduction of the present Pacific plate has worked on Hokkaido, resulting in the complex tectonic setting as shown in Fig. 1.

According to Arita et al. (1998), the geology of Hokkaido is divided into six provinces based on tectonic settings in the Mesozoic (the Oshima, Sorachi-Yezo, Idon'nappu, Hidaka, Tokoro and Nemuro Belts). From this classification, the eastern part of Hokkaido is mainly situated in the Nemuro Belt. The Nemuro Belt is composed of upper Cretaceous to Paleogene sediments (the Nemuro group), Neogene and Quarternary sediments and volcanics. The Nemuro group is exposed in the southern part of study area, as shown in Fig. 2 (Geological Survey of Japan, 1992). These rocks are overlain by Tertiary and Quaternary sediments, forming the Konsen plain, in the southern part of the Nemuro Belt and Miocene to Quaternary volcanic rocks in the northern part of the Nemuro Belt. From a detailed paleocurrent study 


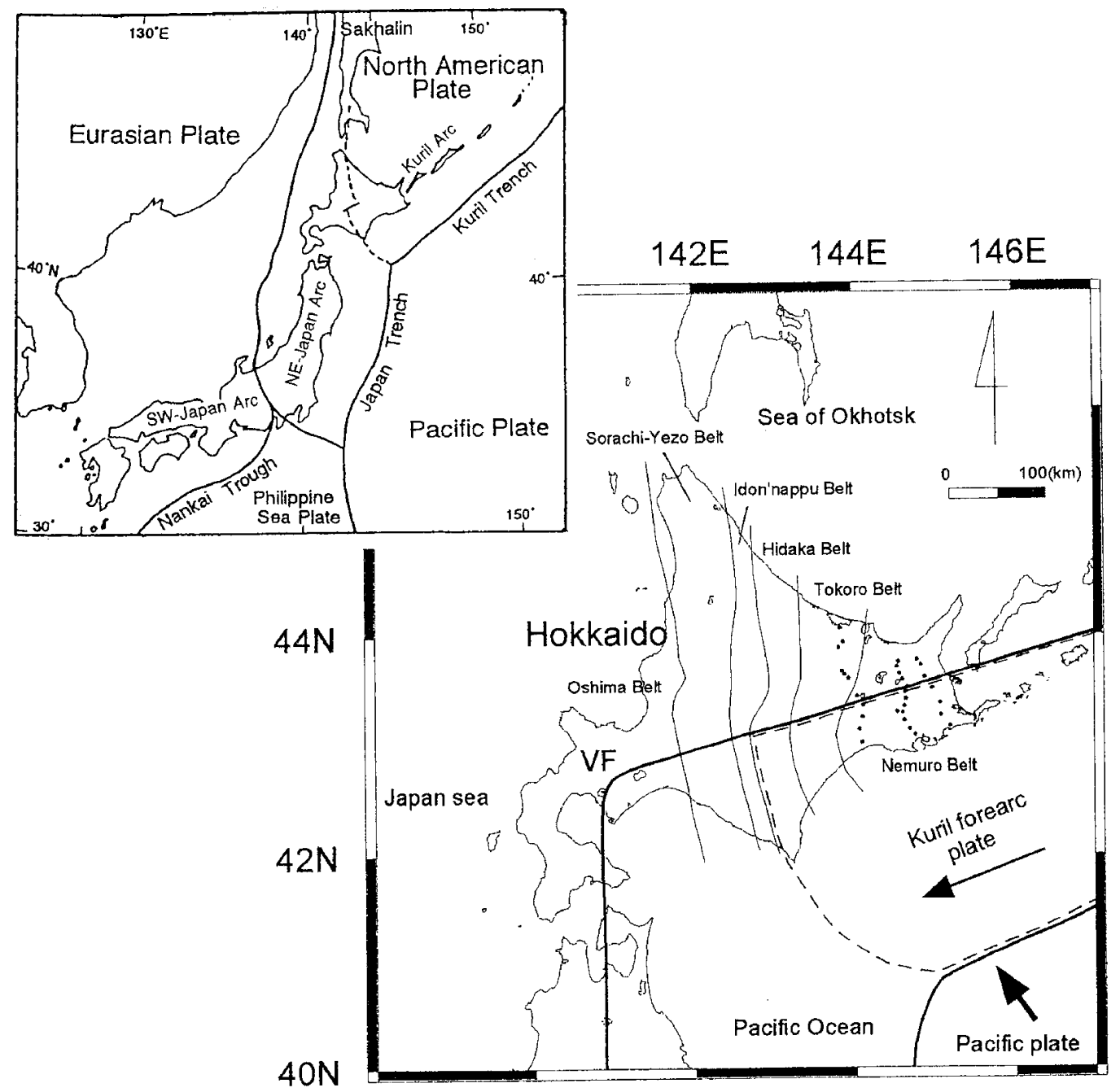

Fig. 1. Tectonic framework in and around Hokkaido, Japan. A thin arrow denotes the direction of the crustal movement caused by the collision of the Kuril Arc against the NE Japan Arc. A bold arrow indicates the subduction direction of the Pacific plate. The conventional MT sites are also shown by small dots. VF indicates the volcanic front.

Kiminami (1983) suggested the Nemuro group was mostly supplied from the north but also partially from the south. These facts strongly suggested that both the Okhotsk Paleoland and the Paleo-Kuril outer arc were located in the north and south of the study area in the late Cretaceous, respectively. Kiminami (1983) indicated that the Okhotsk Paleoland possibly consisted of part of a volcanic arc. However, there was little geophysical evidence to support this hypothesis.

The first electromagnetic study in this region was performed by Mori (1975). Mori measured geomagnetic and geoelectric field variations, which was succeeded by a VLFand ELF-MT survey by the Research Group for Crustal Resistivity Structure (1984). This survey revealed only the shallow sedimentary structure $(<1 \mathrm{~km})$ because the observed frequency range was limited to 8, 14, 20 and 17,400 Hz. Uyeshima (1990) and Uyeshima et al. (2001) performed a network MT study with a long electric dipole (ranging from ten to several tens of kilometers) in the period range from $300 \mathrm{sec}$ to $7,680 \mathrm{sec}$ and proposed a resistivity model of the upper mantle. This new method was realized by employing the commercial telephone network (the detailed methodological explanation of the network MT is referred to in the above-mentioned papers). However, the lack of short period band MT data prevented establishment of the detailed resistivity structure of the crust.

To remedy this situation, we made MT measurements using conventional short electric dipoles (approx. $50 \mathrm{~m}$ electrode spacing) in the period range from $0.003 \mathrm{sec}$ to 1,820 sec. In addition, we re-analyzed the network MT data by Uyeshima (1990); consequently, we analyze wideband MT data in the period range $0.003 \mathrm{sec}$ to $7,680 \mathrm{sec}$. This first attempt at joint analysis of conventional MT and network MT data may provide detailed resistivity structure of the SW end of the Kuril Arc to a depth of about $100 \mathrm{~km}$.

\section{Conventional MT Observation in the Eastern Part of Hokkaido}

Observation: The strike of the Kuril Arc and the elongation of contours of the Bouguer anomaly (Yamamoto and Moriya, 1989; Moriziri et al., 2000) have an ENE-WSW direction (Fig. 3), suggesting that the general tectonic structure is approximately two-dimensional in the eastern part of Hokkaido. We carried out conventional MT surveys in this 


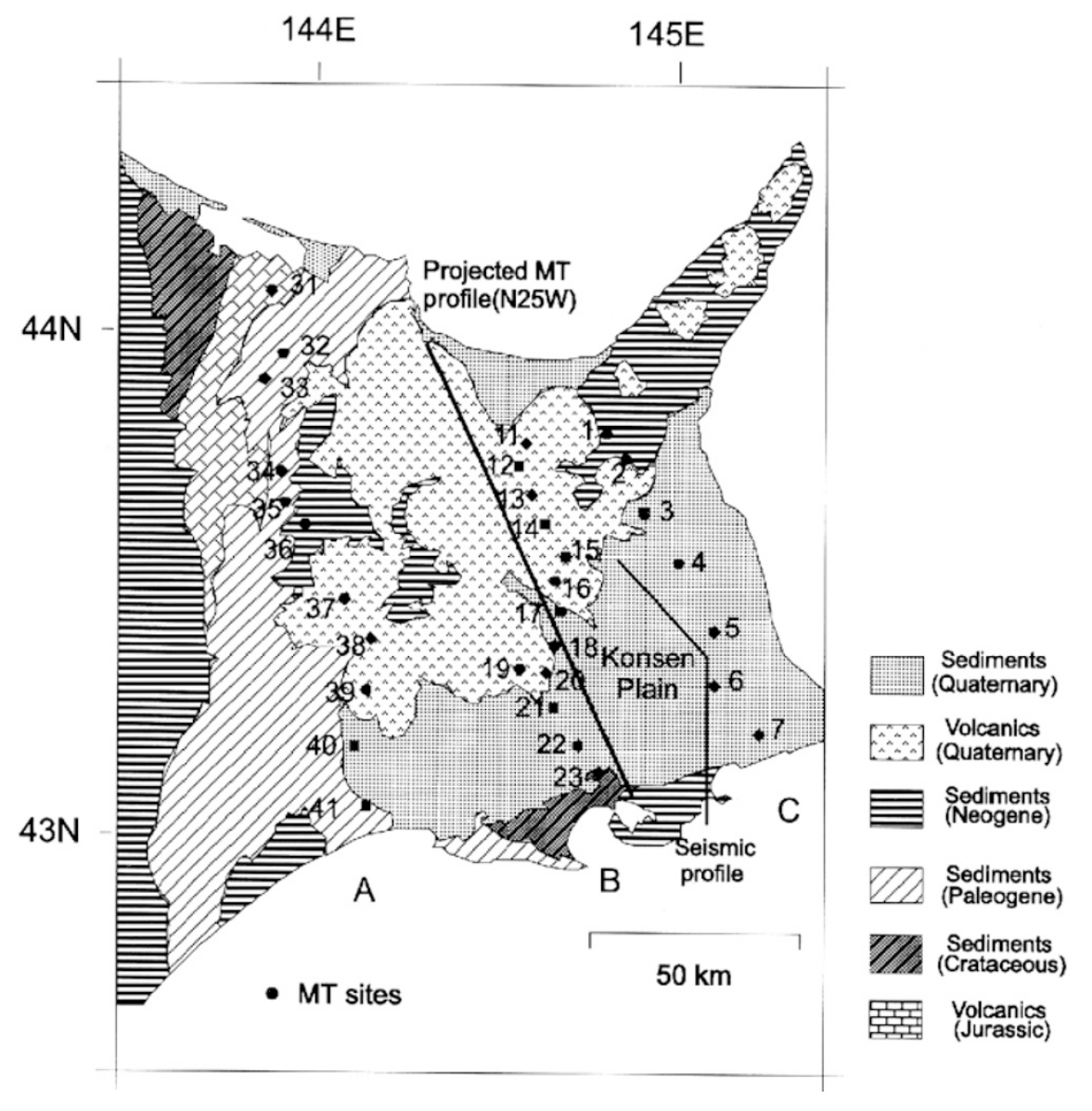

Fig. 2. The conventional MT sites are shown with a simplified geological map (Geological Survey of Japan, 1992). Seismic reflection profile and projected MT profile are also shown by thin and thick solid lines, respectively.

area in 1996 and 1997 using three measurement lines, A-, B- and C-profiles, as shown in Fig. 2. These are aligned in the NNW-SSE direction, which is almost perpendicular to the above mentioned general tectonic trend. The number of observation sites is 31 . We acquired measurements of two-component electric fields and three-component magnetic fields at each site for a period range from $0.003 \mathrm{sec}$ to $1,820 \mathrm{sec}$, using two sets of the V5-MT systems of Phoenix Geophysics Ltd. Data quality of the magnetic and electric fields was remarkably improved at most of the sites by applying a short remote reference method (Gamble et al., 1979).

Estimation of the strike direction: We checked if there is a consistent regional strike for the data set. To deal with the galvanic distortion, we applied the Groom-Bailey tensor docomposition method for each site and period (Groom and Bailey, 1989).

Figure 4 shows the rose histograms of the estimated regional strike directions in four period bands $(0.1-1 \mathrm{sec}, 1-$ $10 \mathrm{sec}, 10-100 \mathrm{sec}, 100-2,000 \mathrm{sec})$. All data in each profile are included in each histogram. Allowing for a $\pi / 2$ ambiguity in strike estimates, there is a general preference of strike direction of $\mathrm{N} 65^{\circ} \mathrm{E}$ or $\mathrm{N} 25^{\circ} \mathrm{W}$ except A-profile. The $\pi / 2$ ambiguity is solved by referring to the induction arrows which are estimated from the three-component magnetic field data. As shown in Fig. 5, induction arrows from
B-profile and the southern end of C-profile tend to point in a NW-SE direction, indicating a NE-SW strike orientation. Comparing the distribution of the induction arrows with the rose histograms, we choose a strike direction as $\mathrm{N} 65^{\circ} \mathrm{E}$. This direction shows good agreement with the strike of the Kuril Arc and the elongated direction of the Bouguer anomaly distribution. Thus, we define here the transverse electric (TE) and transverse magnetic (TM) modes as having the telluric field parallel to and perpendicular to the strike direction of $\mathrm{N} 65^{\circ} \mathrm{E}$, respectively.

Detailed inspection of the induction arrows reveals that arrows in A-profile point in an E-W direction. We interpret this as being due to the complex surface geology, which makes a two-dimensional structural analysis impossible. In the C-profile arrows tend to point towards the neighboring coast line (the coastal effect). Two-dimensionality is not necessarily satisfied due to the coastal effects. It seems that the B-profile may be more two-dimensional than other two profiles and in the present paper, therefore, our attention is mainly focused on this profile.

Two-dimensional resistivity model calculations: The decomposed data are still affected by site gain and anisotoropy, usually called static shift, which appears as a vertical shift of the log apparent resistivity versus period curves relative to the true regional values. If we use the undecomposed apparent resistivity data sets for model calculation, it 


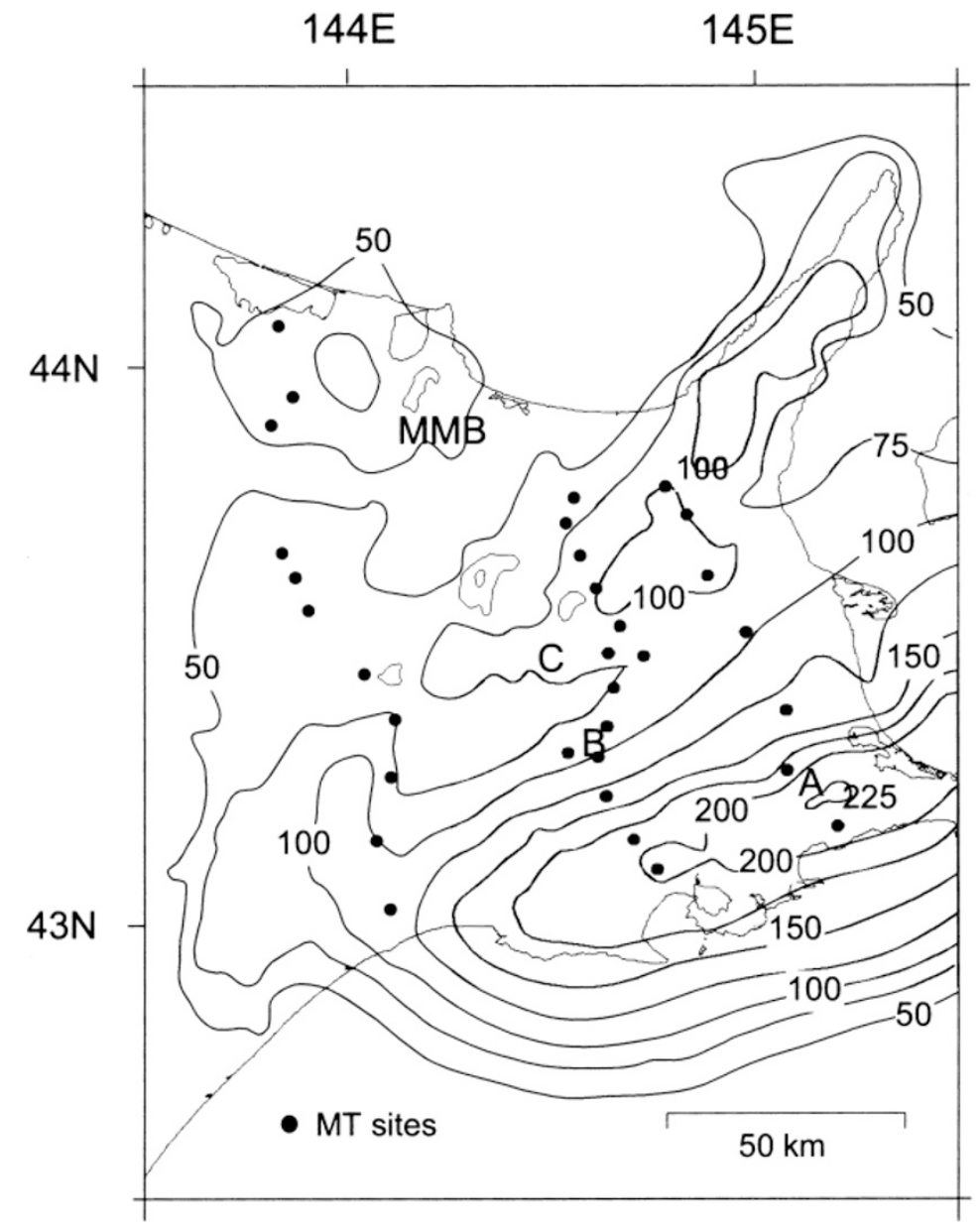

Fig. 3. Distribution of the Bouguer anomaly in and around the eastern part of Hokkaido (modified from Yamamoto and Moriya, 1989). Contour interval is 25 mgal. A, B and C denote drilling sites (Kametani and Yoshimura, 1964; Matsunami and Akita, 1989). MMB shows the location of Memanbetsu Magnetic Observatory.

may lead to a false resistivity structure. Therefore, to construct the resistivity model, we apply the two-dimensional inversion method of Ogawa and Uchida (1996) which includes static shift correction; the static shifts for both TM and TE modes at all sites are treated as model parameters as well as the model resistivities. The misfit between observed and model data is minimized so as to minimize the model roughness and the static shift norms. As these norms have a trade-off relation with each other, the misfit is determined to maximize the Bayesian likelihood: in other words ABIC (Akaike's Bayesian Information Criterion) is minimized. The resistivity structure of the Sea of Okhotsk and the Pacific Ocean is included in the modelling by specifying the bathymetry along the measurement lines and giving sea water a resistivity of $0.25 \Omega \mathrm{m}$.

Models with favorable responses are shown in Figs. 6(a) and 6(b) for the C- and B-profiles, respectively. These models were constructed so as to satisfy the apparent resistivities and phases deduced from the MT data. Beneath the Konsen plain (Fig. 2), a conductive layer (a few to $10 \Omega \mathrm{m}$ ), having a basin structure, occurs to a depth of about $6 \mathrm{~km}$ in the middle to southern part of the B- and C-profiles.

In the middle to lower crust, we can see two common features in the models of the B- and C-profiles. One is a conductive layer (10-40 $\Omega \mathrm{m})$ extending from the volcanic front toward the backarc side in the lower crust. In order to examine whether the existence of this layer is meaningful, we carried out sensitivity tests by replacing the structure below $20 \mathrm{~km}$ in the B-profile by uniform layers of $100 \Omega \mathrm{m}$ and $1,000 \Omega \mathrm{m}$. The test responses showed little change in the forearc side in comparison with the best fit responses. In the backarc side, on the contrary, the apparent resistivity and the phase responses of TM mode gave worse fit for periods longer than several ten sec as shown in Fig. 7. Therefore, it can be safely concluded that the lower crust in the backarc side is significantly conductive.

The second feature is a highly resistive layer (more than $10,000 \Omega \mathrm{m}$ ) distributed in the southern part of the study area (the forearc side) in the middle to lower crust. The bottom boundary of this layer is estimated as $30 \mathrm{~km}$ or so in depth. We also carried out the sensitivity test by replacing the depth of the bottom boundary by $40 \mathrm{~km}$ in the B-profile. This test showed negligible change in the test responses of apparent resistivity and phase in all observation sites, suggesting that the bottom boundary was poorly determined. To overcome such limitation, we need more longer period data than 1,820 sec. We, therefore, re-analyzed the network MT data which cover a period range from $300 \mathrm{sec}$ to $7,680 \mathrm{sec}$. We will 

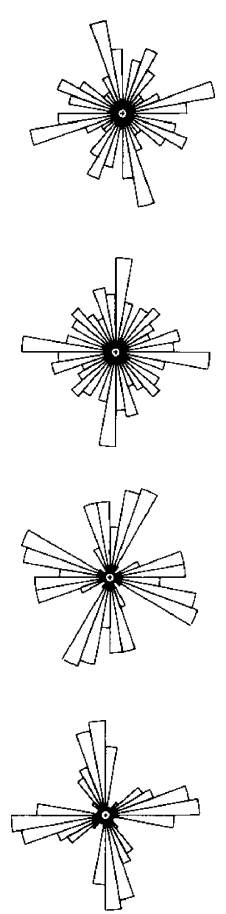

A-profile
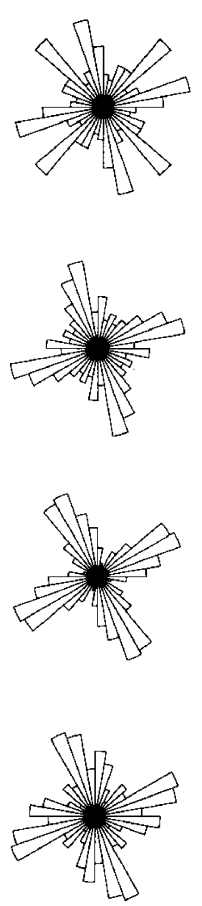

B-profile

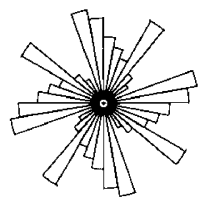

$0.1-1 \mathrm{sec}$

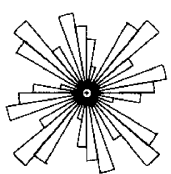

$1-10 \mathrm{sec}$

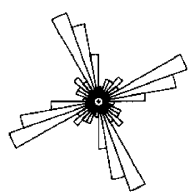

$10-100 \mathrm{sec}$

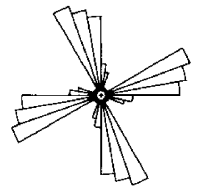

$100-2000 \mathrm{sec}$

Fig. 4. Rose histograms of the estimated strike directions after Groom-Bailey decomposition. The histograms are grouped in four period bands. Upper direction denotes north for each rose.

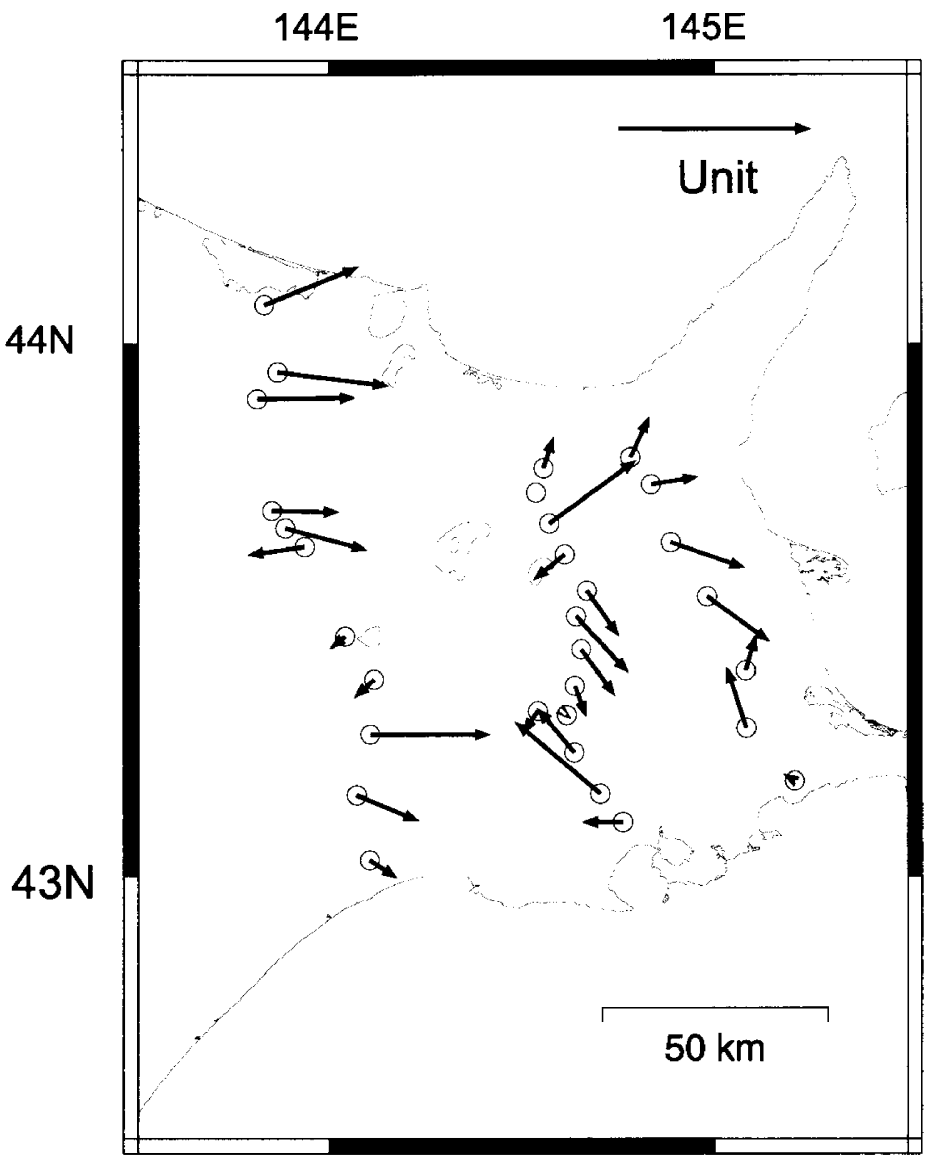

Fig. 5. Distribution of the induction arrows at a period of $100 \mathrm{sec}$, derived from the real part of the geomagnetic transfer functions. 
(a)
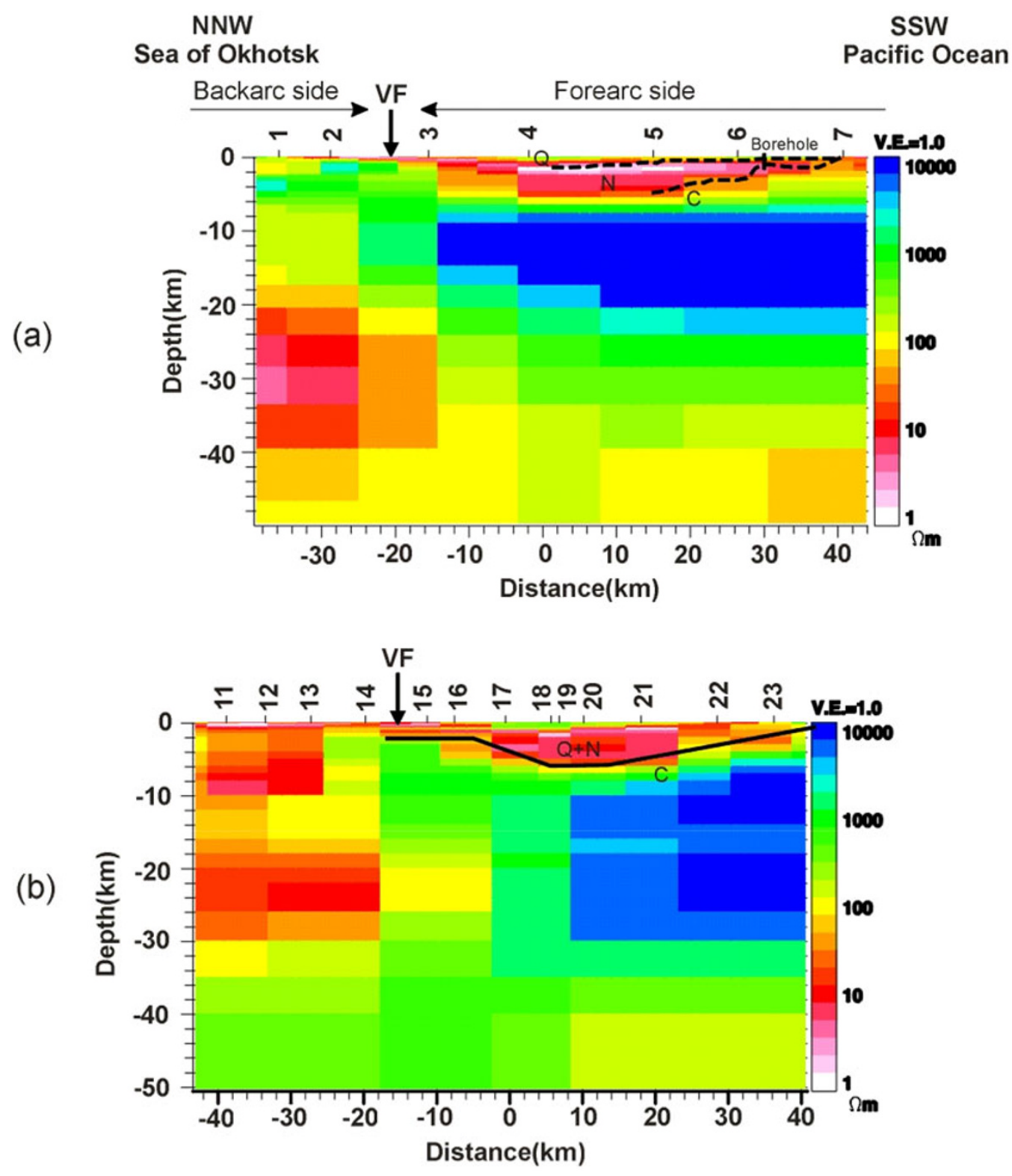

Fig. 6. Resistivity models deduced from the conventional MT survey: (a) C-profile and (b) B-profile. Dashed curves in (a) represent the seismic reflectors, while solid curve in (b) represents the boundary of the Neogene and the Cretaceous layers inferred from the gravity analysis. Q, N and C denote the Quaternary, Neogene and Cretaceous layers, respectively. VF indicates the volcanic front.

present the procedure of the network MT data re-analysis in the next chapter.

\section{Data Processing of the Network MT Data}

The network MT method is designed to acquire largespatial and averaged resistivity information by using long electric dipole lengths (ranging from ten to several tens of kilometers), associated with the telephone cable nets of NTT (Nippon Telegraph and Telephone Corporation) (Uyeshima, 1990; Uyeshima et al., 2001). Figure 8 shows the distribution of the network MT nets (triangular sections) together with the conventional MT sites. The method ensures the electric fields have a high signal to noise ratio. This is because the electric potential difference is enhanced due to the long dipole length, while the noise in the electric field is locally limited near the electrodes.

We recorded the electric fields every one minute using several digital data loggers which were installed at each central telephone station. To estimate the response functions for each dipole, we used horizontal magnetic fields recorded at Memanbetsu Magnetic Observatory (MMB in Fig. 3), situated at $150 \mathrm{~km}$ distant from the present observation sites in maximum. We calculate the response functions between the electrical potential difference and the magnetic field for each dipole and then obtain the impedance tensors for each triangular section (Fig. 8). The relationship between voltage difference for each dipole and two magnetic fields in the frequency domain can be described by the following linear relation:

$$
V(\omega)=V_{\mathrm{NS}}(\omega) \cdot H(\omega)+V_{\mathrm{EW}}(\omega) \cdot D(\omega)
$$

where $V(\omega)$ is the observed voltage difference for each dipole, $V_{\mathrm{NS}}(\omega)$ and $V_{\mathrm{EW}}(\omega)$ are the response functions. 

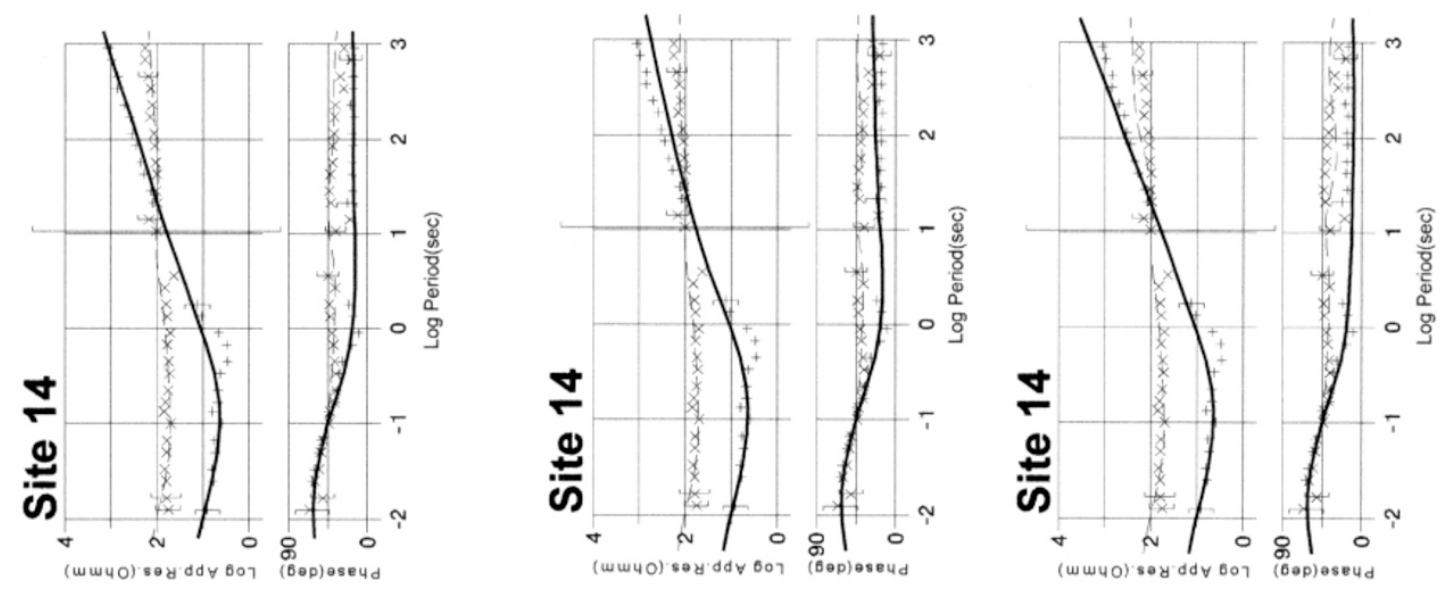

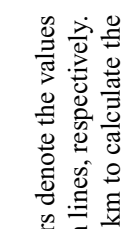
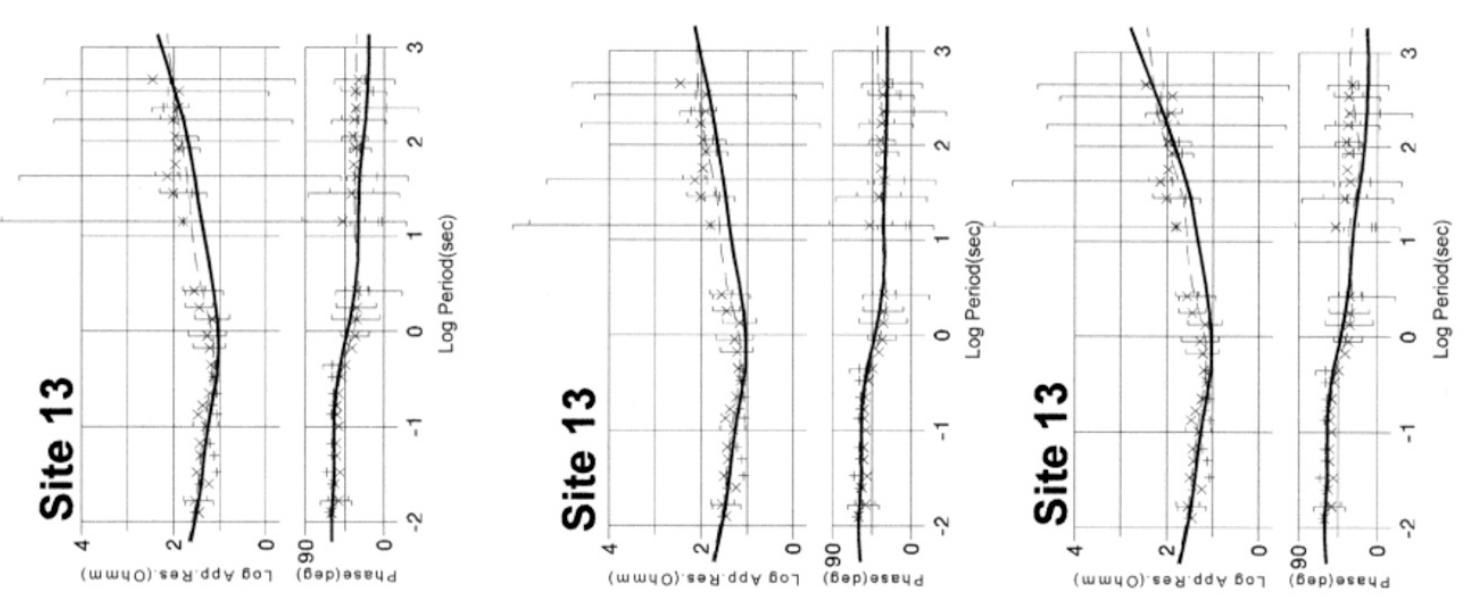

爱
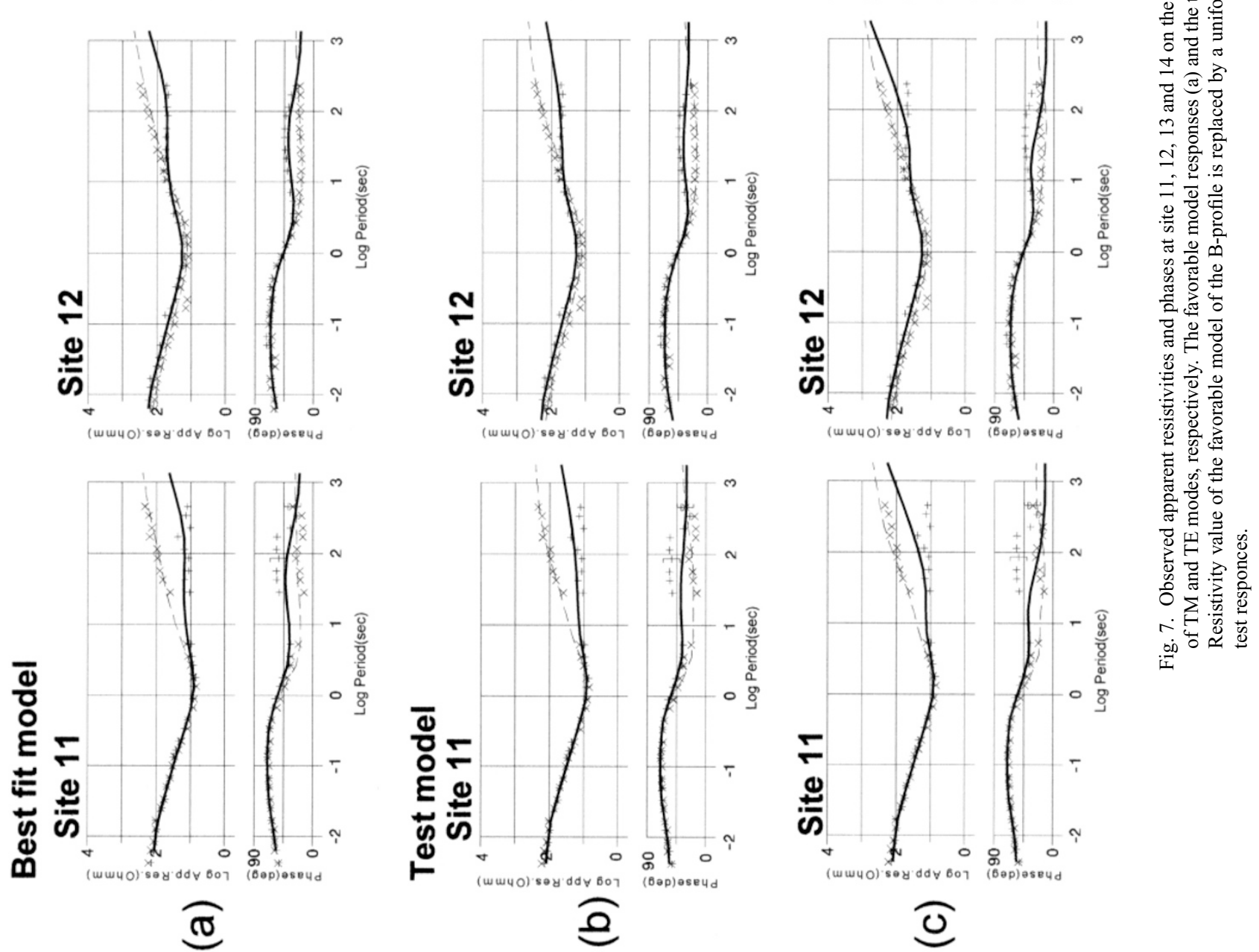


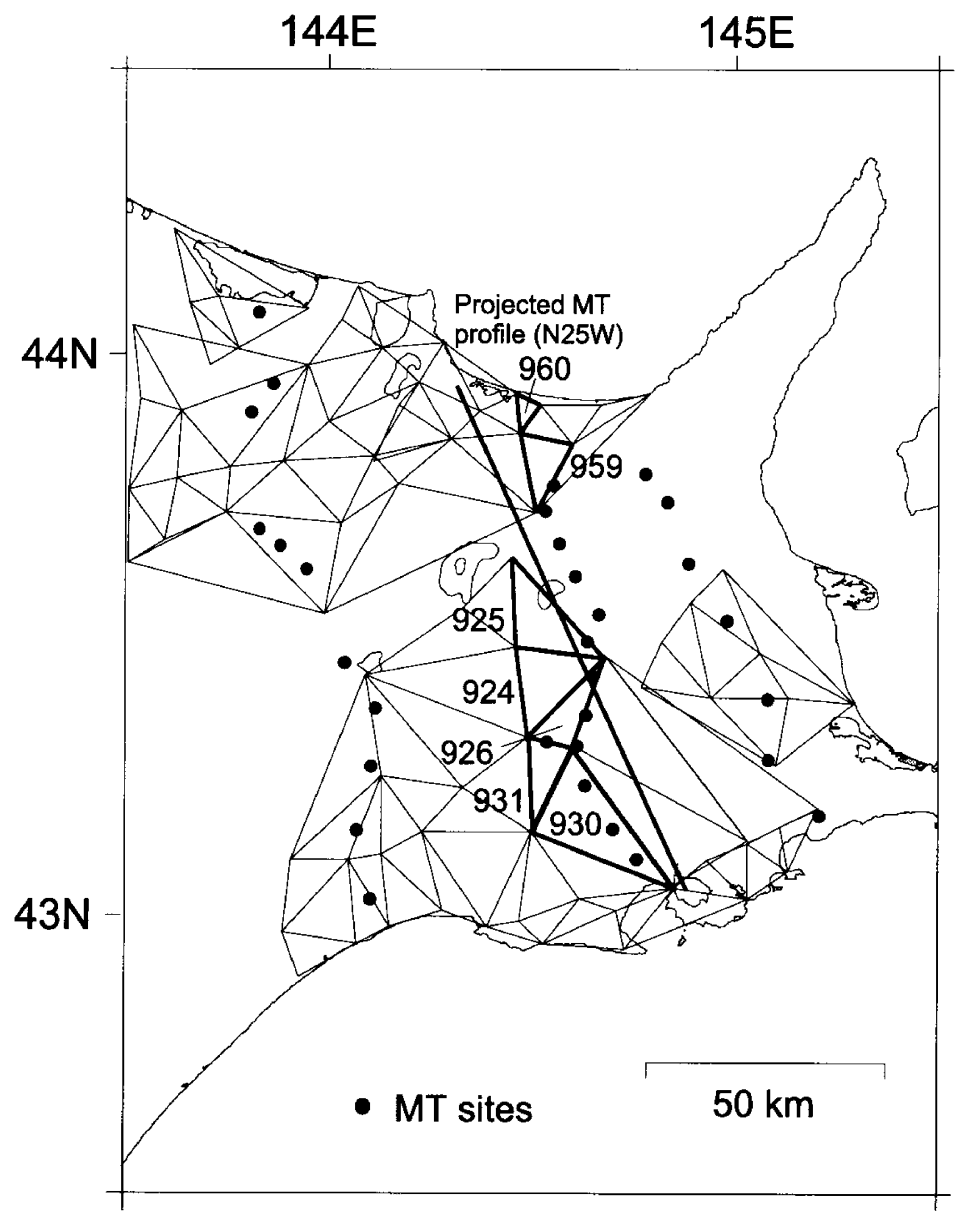

Fig. 8. Distribution of the network MT nets (triangles) and the conventional MT sites (solid circles). Bold triangular sections with numbers are used in the modeling of the present study.

$H(\omega)$ and $D(\omega)$ are the NS and EW components of horizontal magnetic fields, respectively. $V_{\mathrm{NS}}(\omega)$ and $V_{\mathrm{EW}}(\omega)$ determined by the observed $V(\omega), H(\omega)$ and $D(\omega)$ are used to calculate the impedance tensors which are expressed by a linear combination of the two response functions. Time series raw data were filtered through digital band pass filter (Saito, 1978) with pass band from 5 to 200 minutes. The filtered data were divided into some data sets. These data sets were transformed to the frequency domain by Fast Fourier Transformation (FFT). The response functions, $V_{\mathrm{NS}}(\omega)$ and $V_{\mathrm{EW}}(\omega)$, were calculated using the least square method for the period range from 5 to 128 minutes.

To estimate the regional strike direction, we applied the Swift's (1967) method for each triangular net shown by bold lines in Fig. 8. Figure 9 shows the rose histograms in two period bands $(300-1,000,1,000-10,000 \mathrm{sec})$. The estimated strike direction is well consistent with that of the conventional MT impedance as shown in Fig. 4, that is, $\mathrm{N} 65^{\circ} \mathrm{E}$ or $\mathrm{N} 25^{\circ} \mathrm{W}$.

\section{Two-Dimensional Resistivity Model Deduced from a Joint Analysis of the Conventional MT and Network MT Data}

Strike direction as determined by each triangular net, as shown in Fig. 9, was almost coincide with that deduced from the conventional MT data. Therefore, in order to improve the model resolution and to establish a detailed resistivity structure from the surface to the upper mantle, the apparent resistivity and phase responses based on the conventional MT and network MT data have been inverted together to give a two-dimensional resistivity model. In the present study, we used the triangular nets shown in bold in Fig. 8 along the B-profile.

We show a resistivity model with favorable responses and its simplified expression in Figs. 10(a) and 10(b), respectively. The model responses are shown with the observed

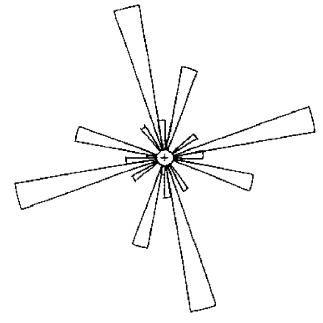

$300-1000(\mathrm{sec})$

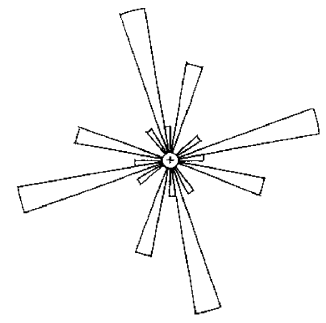

$1000-10000$ (sec)
Fig. 9. Rose histograms of the estimated strike directions determined by network MT impedance tensors. The histograms are grouped in two period bands. Upper direction denotes the north for each rose. 


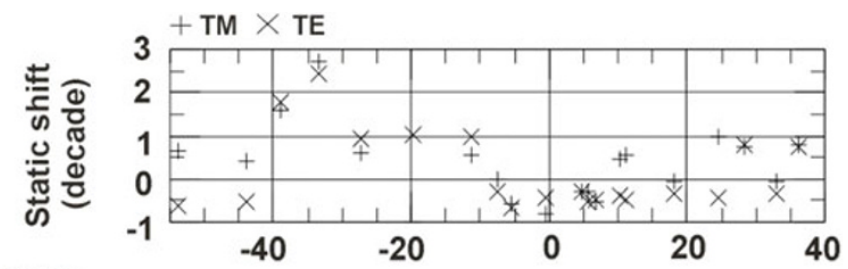

NNW

Sea of Okhotsk

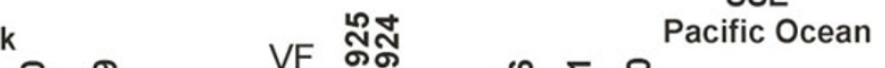

Pacific Ocean

(a)

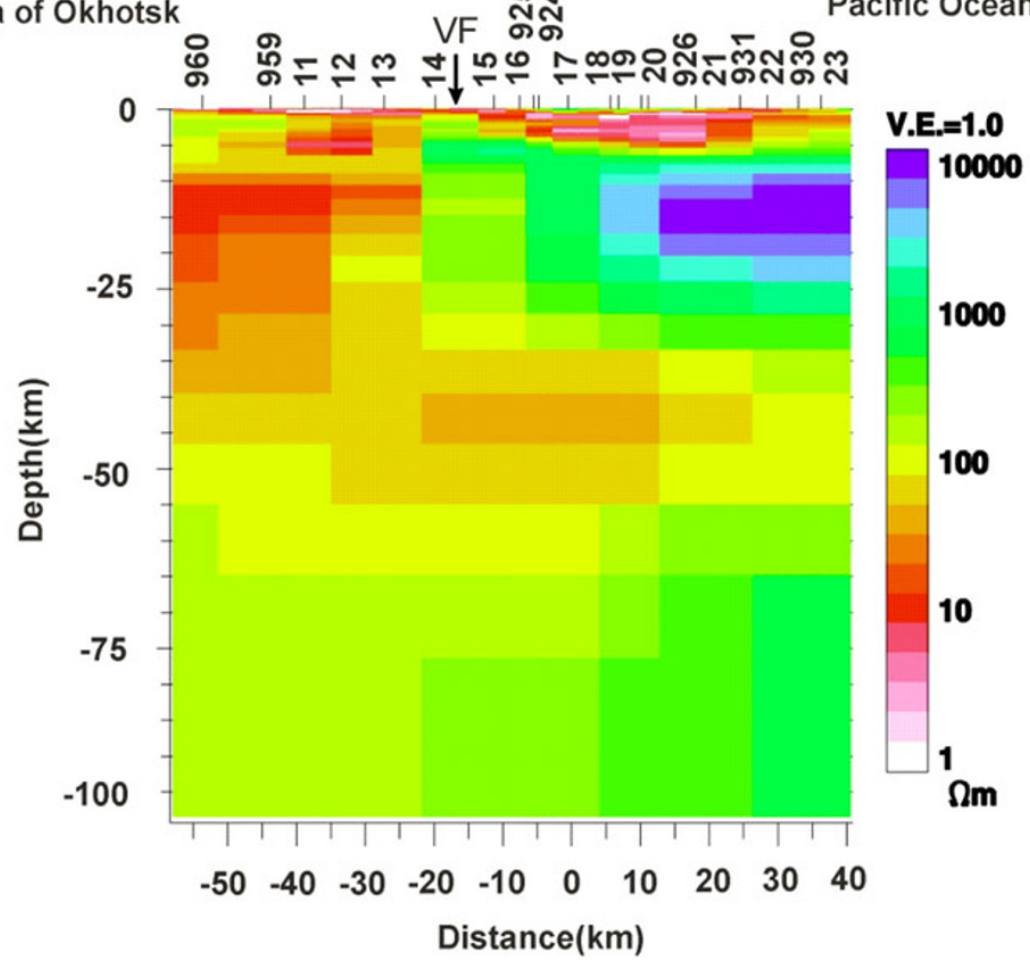

NNW

Sea of Okhotsk

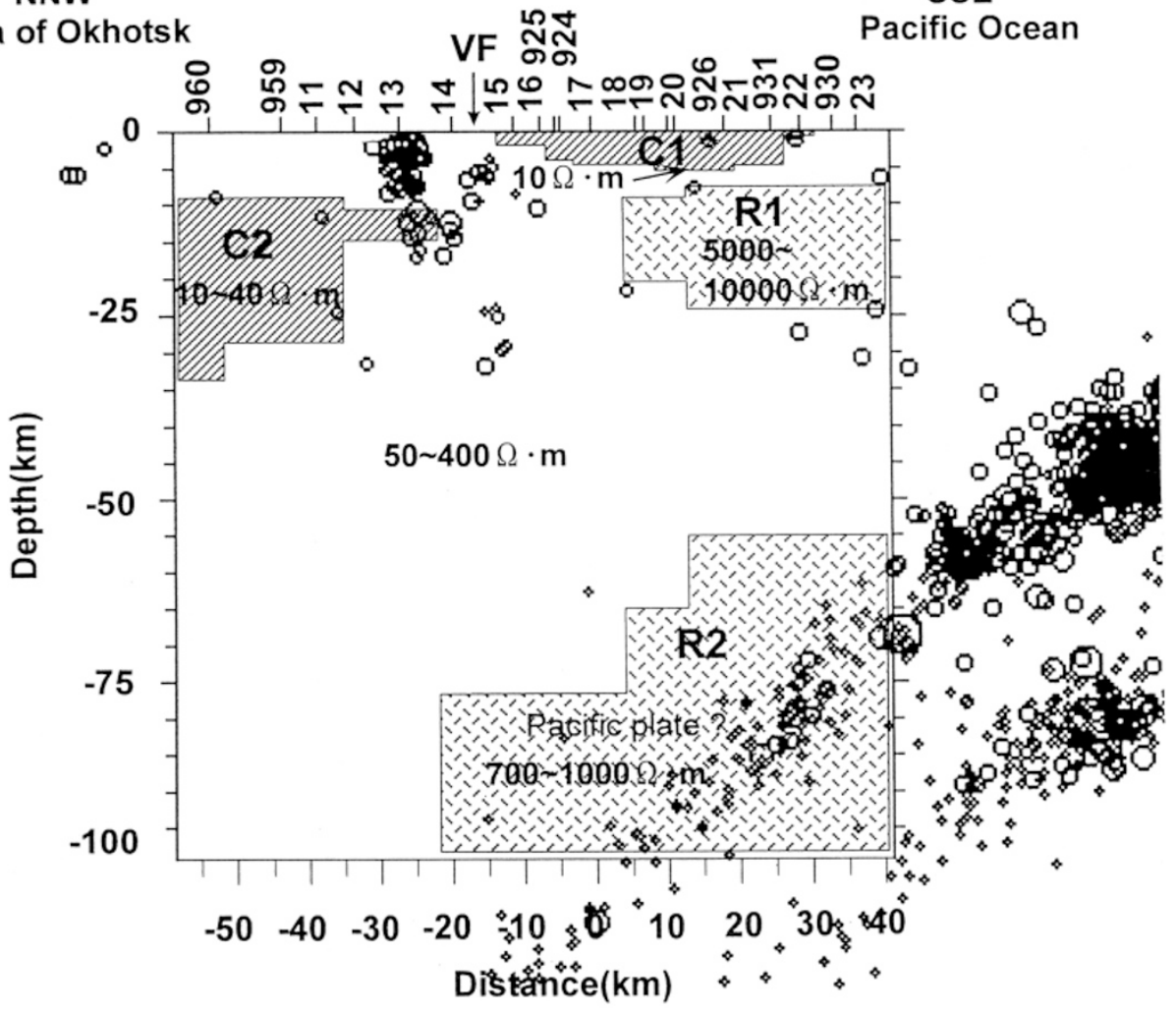

Fig. 10. (a) Final two-dimensional resistivity model along the B-profile (lower part). VF indicates the volcanic front. Static shifts for TM (plus) and TE (cross) modes are also shown (upper part). (b) Simplified resistivity model. C and R with number represent a conductor and a resistor, respectively. Hypocenter distribution is also shown. 


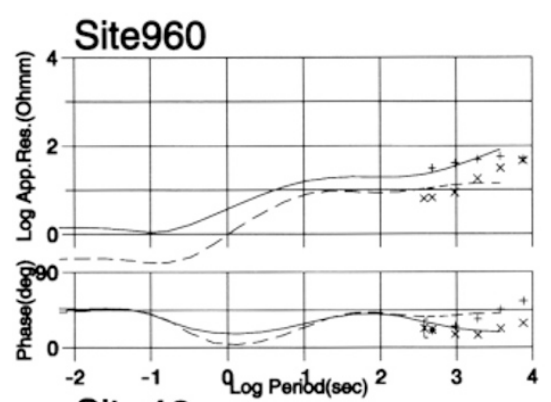

Site 12
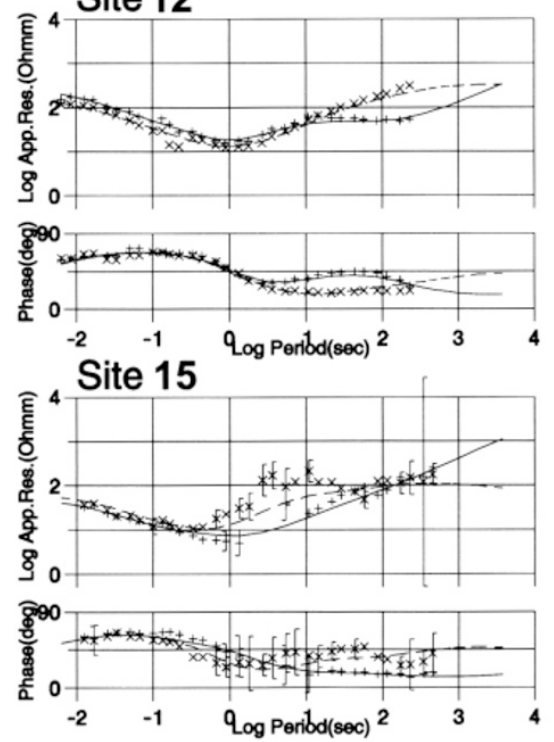

Site959

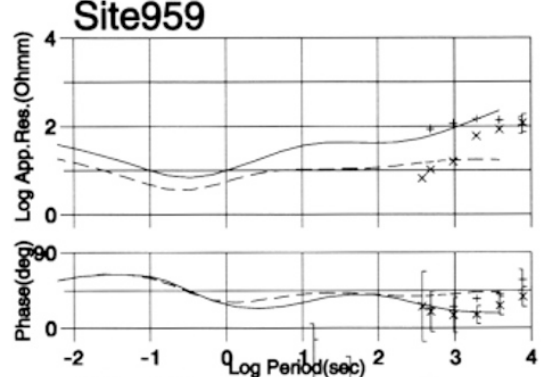

Site 13

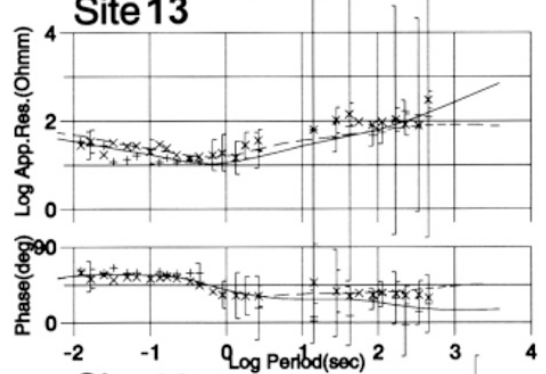

Site 16

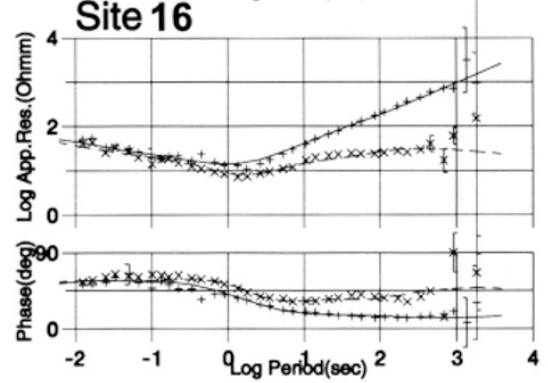

Site11

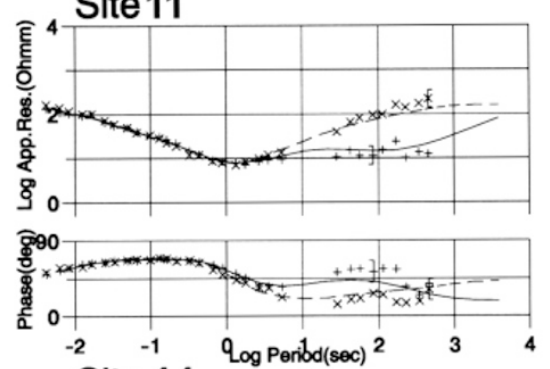

Site 14

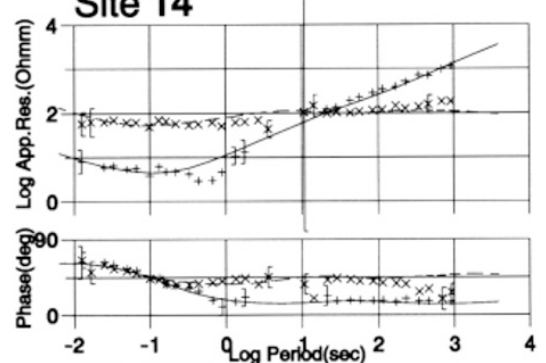

Site925

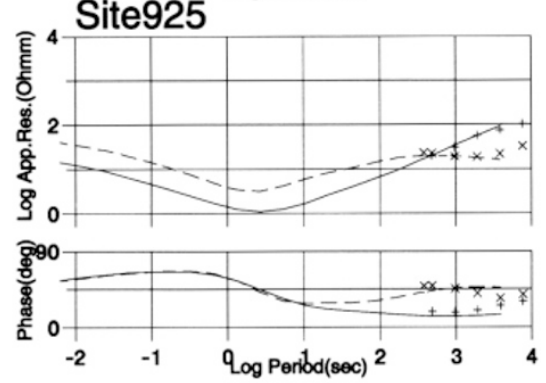

Fig. 11. Observed apparent resistivities and phases at all sites on the B-profile. Plus $[+]$ and cross $[\times]$ signs with error bars denote the value of TM and TE modes, respectively. The favorable model responses are also shown by solid (TM) and broken (TE) curves.

apparent resistivities and phases in Fig. 11. The results show that we do not need any serious revision of the two conductive layers in the previous model determined only from the conventional MT data: the surface conductive layer $(\mathrm{C} 1)$ and the lower crustal conductive layer (C2). As we lack the short period data by the conventional MT observations within the areas of the network MT nets 960 and 959, it is difficult to clarify the extent of the $\mathrm{C} 2$ layer from the site 11 towards the back arc side. Distribution of the resistive layer $(5,000$ $10,000 \Omega \mathrm{m})$ in the southern part of the study area is well determined in a depth range from 10 to $25 \mathrm{~km}$ (R1).

The resistivity of the upper mantle is estimated as 40 $100 \Omega \mathrm{m}$. In addition, we propose a relatively resistive layer $(700-1,000 \Omega \mathrm{m})$ distributed in the southern part of the study area at depths from about 55 to $100 \mathrm{~km}$ (R2). A sensitivity test replacing the structure below $46 \mathrm{~km}$ by a uniform layer of $100 \Omega \mathrm{m}$ showed little change in the test responses in the backarc sites in comparison with the best fit responses. However, at the forearc sites, the phase responses of the TM mode showed considerably worse fit at longer periods than $10 \mathrm{sec}$. Thus, the model requires the resistive layer at depths from 55 to $100 \mathrm{~km}$.

\section{Discussion}

A conductive layer (a few to $10 \Omega \mathrm{m}$ ) beneath the Konsen plain is distributed widely and thickly in the middle to southern part of the study area. The maximum depth to the bot- tom of this conductor is estimated as about $6 \mathrm{~km}$. According to geological investigations (e.g., Satoh and Yamaguchi, 1976), the study area is mainly composed of Quaternary and Neogene sediments underlain by upper Cretaceous formation, lacking the Paleogene formation. Most of the Neogene sediments in Japan produce large amounts of alteration minerals (e.g., kaolinite, chlorite, alunite, sericite, montmorillonite and so on) affected by diagenesis (Shirozu, 1988). These altered minerals reduce the rock resistivity (Sen et al., 1988; Takakura, 1995). The Neogene sediments may therefore play a key role as the origin of this conductor.

A recent seismic reflection survey along the solid line in Fig. 2 (Hokkaido Mining Promotion Committee, 1990) depicted the detailed reflectors shown in Fig. 6(a). Analysis of drill cores at Nishibetsu (A in Fig. 3) identifies the strongest reflector as a boundary between the Neogene and the Cretaceous periods (Kametani and Yoshimura, 1964). This reflector agrees well with the bottom of the conductive layer. In Fig. 12, we show the Bouguer gravity anomalies relative to the maximum values (Yamamoto and Moriya, 1989). We made a two-dimensional modeling of the density structure (Talwani et al., 1959) by a trial and error method as also shown in Fig. 12. The core density-depth relation obtained at three drilling sites $\mathrm{A}, \mathrm{B}$ and $\mathrm{C}$ were given in the modeling procedure. The result reveals that the maximum depth of the boundary between the Neogene and the Cretaceous periods is estimated as about $6 \mathrm{~km}$ as shown in Fig. 12 and 

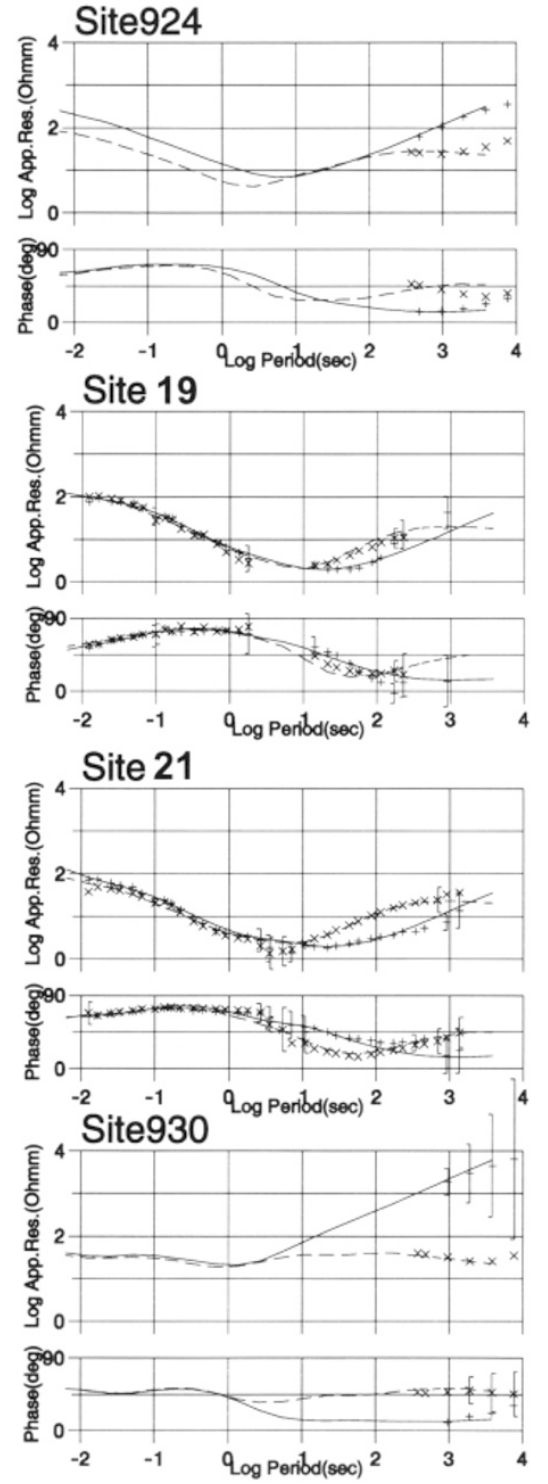
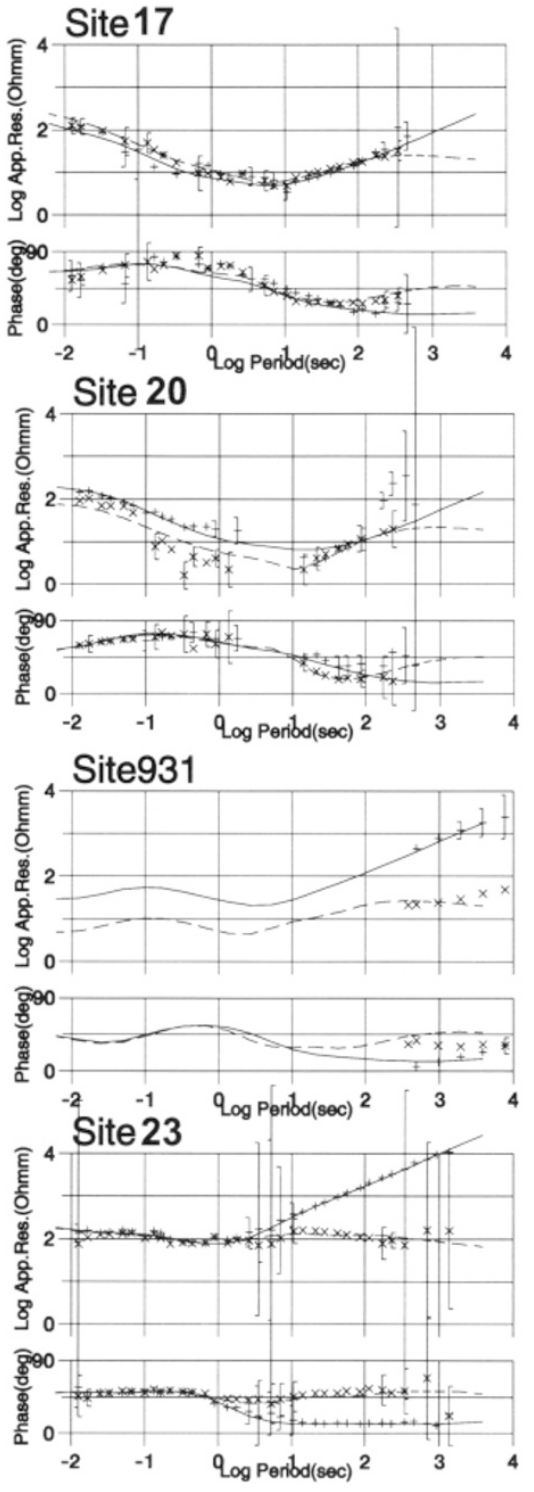

Fig. 11. (continued).
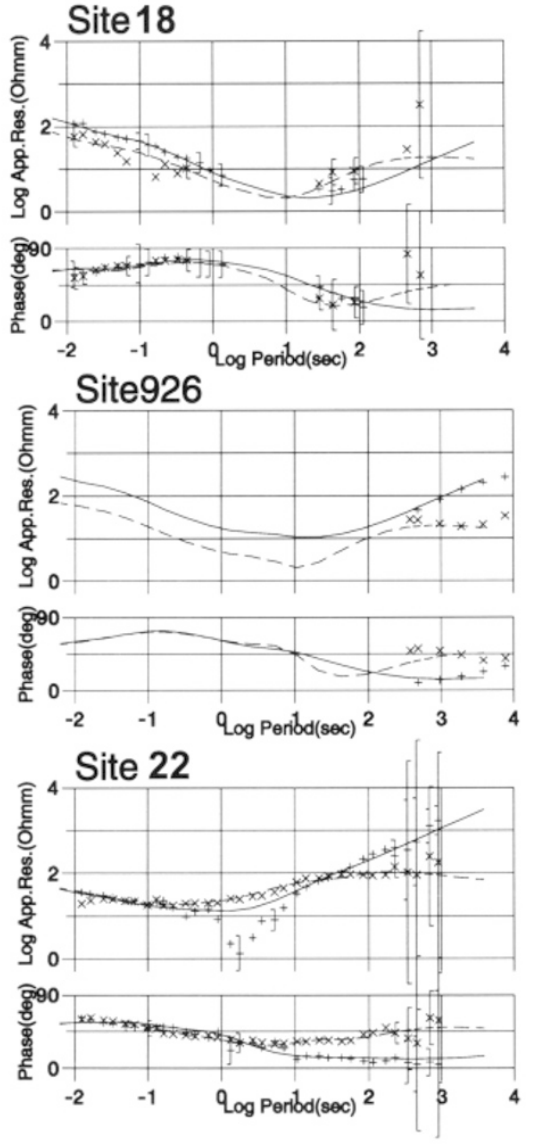

Fig. 6(b). The seismic and gravity analyses strongly suggest that the causative material of the upper crustal conductive layer is the Neogene sediments.

Utada et al. (1996) proposed a conductive layer (a few to $30 \Omega \mathrm{m}$ ) in the lower crust of NE Japan. We also found a conductive layer (10-40 $\Omega \mathrm{m})$ in the lower crust, extending from the volcanic front toward the backarc side. Such conductive layers have been reported in several subduction zones; for examples, the NE Japan Arc, the Nazca plate, the Juan de Fuca plate (e.g., Ogawa, 1987; Hyndman, 1988; Jones, 1992; Marquis et al., 1995; Utada et al., 1996). The cause of the lower crust conductive layer is not fully understood. However, there are several possible explanations: conductive minerals (e.g., graphite), fluids (e.g., ionized free water) and partial melt of rocks. Among these candidates, conductive minerals have not been reported in the present study area. Okubo (1999) calculated the temperature distribution in the crust of the study area, assuming granite in the upper crust and amphibolite and water unsaturated gabbro in the lower crust. The result is that the temperature attains to the solidus temperature $\left(900^{\circ} \mathrm{C}\right)$ of the lower crustal rocks in the backarc side because of the high terrestrial heat flow $\left(>120 \mathrm{~mW} / \mathrm{m}^{2}\right)$. Therefore, the origin of the lower crust conductive layer is probably ascribed to the effect of partial melting of the crustal rocks. However, we cannot rule out the effect of the trapped free water supplied from the subducting plate. It can be considered that both of these play a role in forming the low resistive crust as the presence of water decreases the melting temperature of the rocks (e.g., Wyllie, 1971) to facilitate the network-formation of melt.

We found a highly resistive layer (5,000-10,000 $\Omega \mathrm{m})$ distributed in the southern part of the study area (forearc side). This is an important result of the present study. The distribution of the resistive layer is consistent with that of the large and positive gravity anomaly (Fig. 3), suggesting that the causative material is common. The existence of this layer may be related to the collisional event between the Eurasia plate and the Okhotsk Paleoland in the Cretaceous pe- 


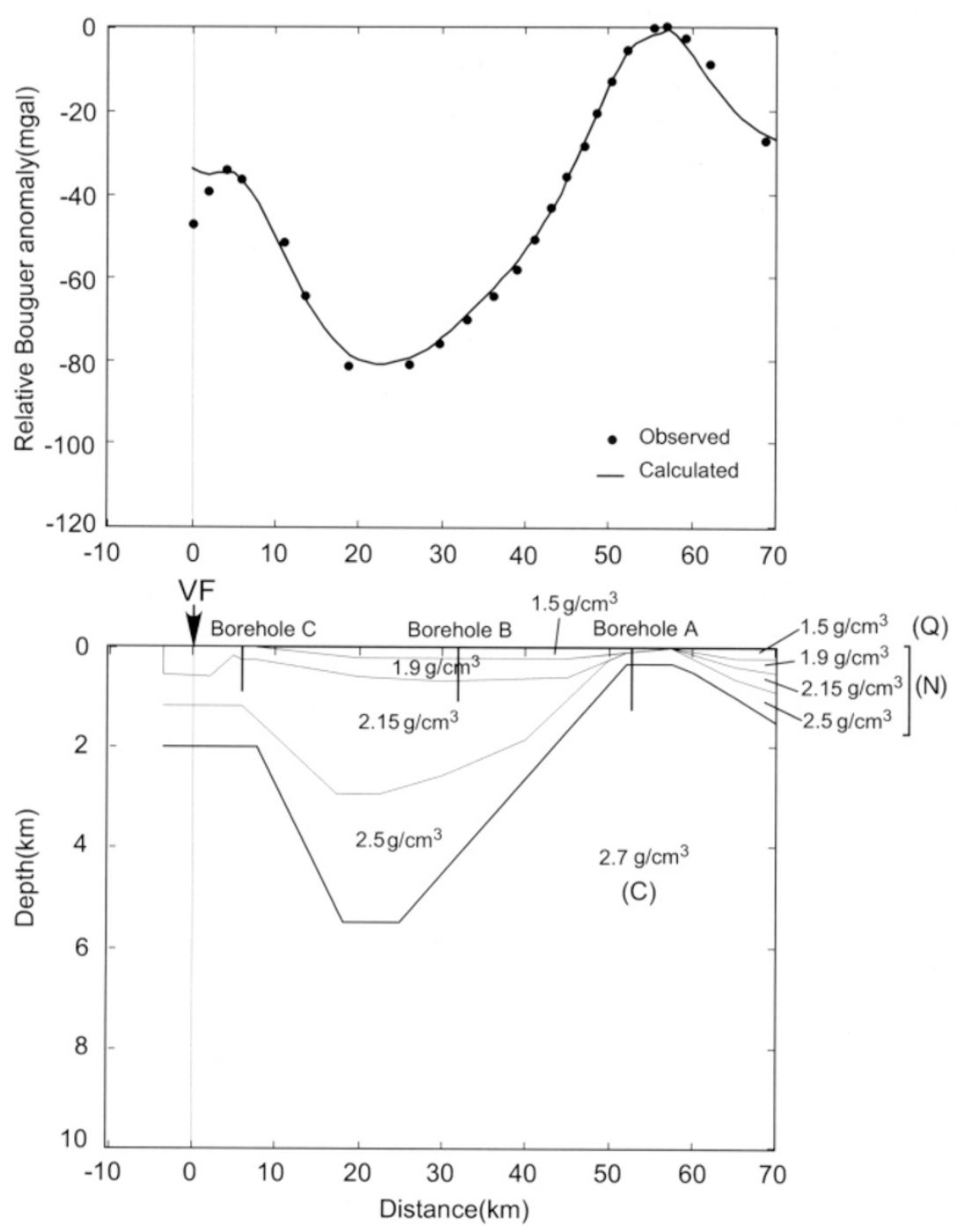

Fig. 12. A comparison of observed and calculated Bouguer anomalies along the B-profile (upper part). VF indicates the volcanic front. Observed and calculated values are shown by the solid circles and solid line, respectively. A density model are also shown (lower part). Q: Quarternary; N: Neogene; C: Cretaceous.

riod, although the detailed tectonic implications are left to be solved.

The upper surface of the relatively high resistive layer (700-1,000 $\Omega \mathrm{m}$ ) tends to be deeper towards the north (deepening from 55 to $100 \mathrm{~km}$ within the study area). Hypocenter distribution determined by the Institute of Seismology and Volcanology, Hokkaido University, is plotted on the resistivity model in Fig. 10(b). In the study area, seismic activity can be classified into two main groups according to the hypocenter distribution. Vertically distributed seismic activity is found from the surface to $20 \mathrm{~km}$ in depth near site 13 . These earthquakes under the Quarternary volcanoes may be mainly caused by the present tectonic movement of the collision between the Kuril forearc sliver and the NE-Japan forearc (Moriya, 1986). Deeper activity forming double seismic planes dips to north, indicating the subducting Pacific plate motion (Suzuki et al., 1983). Thus the resistive layer is probably identified as a part of the Pacific plate. The resistivity value is almost consistent with that found in the NE-Japan
$\operatorname{Arc}(500 \Omega m)$.

In the present study, we could not define a thin conducting layer on the top of the subducting plate, as found in NE Japan (Utada et al., 1996) and SW Japan (Yamaguchi et al., 1999). Utada et al. (1996) and Yamaguchi et al. (1999) gave a priori structural boundaries, such as the plate configuration and the Moho boundary, based on seismological evidence, and estimated the resistivity of each structure so as to interpret the observed electromagnetic data. This method of analysis could enable the identification of a thin conducting layer on the top of the subducting plate. However, we did not assume a priori structural boundaries and, therefore, a resolution of modeling is too crude to delineate such a thin conducting layer.

\section{Conclusions}

The first attempt of the joint analysis of conventional MT and network MT data successfully delineates detailed resistivity structure in the eastern part of Hokkaido, Japan to a 
depth of about $100 \mathrm{~km}$. The resistivity model is characterized as follows;

(1) In the upper crust, a conductive layer (a few to 10 $\Omega \mathrm{m}$ ), having a basin structure, is distributed widely in the middle to southern part of the study area to a maximum depth of about $6 \mathrm{~km}$. Considering the results of seismic, gravity and drill core analyses, the bottom of this layer is interpreted to the boundary of the Neogene and the Cretaceous sediments.

(2) A conductive layer (10-40 $\Omega \mathrm{m})$ extending from the volcanic front toward the backarc side is situated in the lower crust, in common with a similar feature in the NEJapan Arc (a few to $30 \Omega \mathrm{m}$ ). The origin of the conductive layer is not fully understood but the partial melting of rocks is a candidate because of the high terrestrial heat flow in this region. Trapped free water may not be ruled out as the origin of the conductive layer. Both effects are possible because the existence of free water decreases the melting temperature of the rocks.

(3) In the middle to lower crust, a highly resistive layer (more than 10,000 $\Omega \mathrm{m}$ ) is found in the forearc side of the study area. The distribution of this layer is consistent with that of a high positive gravity anomaly, suggesting that the causative material is common, although the material cannot be identified at present. This resistive layer should be taken into account when we construct the tectonics of the present study area.

(4) The resistivity of the upper mantle is 40-100 $\Omega \mathrm{m}$.

(5) The resistivity of the Pacific plate is indicated to be 700-1,000 $\Omega \mathrm{m}$. These values are almost the same as that for the NE-Japan Arc $(500 \Omega \mathrm{m})$.

Acknowledgments. We are very thankful to Dr. Mitsuru Utsugi, Messrs. Kengo Tanimoto, Takahiro Maeda and Makoto Tamura (Hokkaido University) for their great efforts in the field work. We also thank Prof. Toshiyasu Nagao (Tokai University) for supporting this study. We are deeply indebted to the staff of Nippon Telegraph and Telephone Corporation (NTT) for their support and assistance for the network MT observation. This research was partly supported by a science grant from Earthquake Research Institute (ERI) of the University of Tokyo and RIKEN, International Frontier Program on Earthquakes. Thanks are due to Dr. C. K. Rao (Indian Institute of Geomagnetism) for reading the manuscript and making a number of helpful suggestions. Critical and constructive reviews by Malcolm Ingham and anonymous reviewer improved the manuscript.

\section{References}

Arita, K., T. Iwasaki, T. Ito, A. Yamamoto, M. Saito, Y. Nishida, H. Satoh, G. Kimura, T. Watanabe, T. Ikawa, and T. Kuroda, Crustal structure and tectonics of the Hidaka collision zone, Hokkaido (Japan), revealed by vibroseis seismic reflection and gravity surveys, Tectonophys., 290, 197210, 1998.

Fuji-ta, K., Y. Ogawa, S. Yamaguchi, and K. Yasukawa, Magnetotelluric imaging of the SW Japan forearc-a lost paleoland revealed ?, Phys. Earth Planet. Inter, 102, 231-238, 1997.

Gamble, T. D., W. M. Goubau, and J. Clarke, Magnetotellurics with remote magnetic reference, Geophysics, 44, 53-68, 1979.

Geological Survey of Japan, 1:1,000,000 Geological map of Japan, third ed., 1992.

Groom, R. W. and R. C. Bailey, Decomposition of magnetotelluric impedance tensors in the presence of local three dimensional galvanic distortions, J. Geophys. Res., 94, 1913-1925, 1989.

Hokkaido Mining Promotion Committee, Konsen region. in: Petroleum and Natural Gas Resources-Their Exploration and Development (1977-1988)—* , 131-135, 1990 (in Japanese).
Honkura, Y., Electrical conductivity anomalies beneath the Japan Arc, J. Geomag. Geoelectr., 26, 147-171, 1974.

Hyndman, R. D., Dipping seismic reflections, electrical conductive zones, and trapped water in the crust over a subducting plate, J. Geophys. Res., 93, 13391-13405, 1988.

Jones, A. G., Electrical conductivity of the continental lower crust, in Continental Lower Crust, pp. 81-143, Elsevier, Amsterdam, 1992.

Kametani, T. and Y. Yoshimura, Geophysical history of Nemuro-Kushiro region, Butsuri-Tanko (Geophys. Exploration), 17, 82-91, 1964 (in Japanese with English abstract).

Kato, Y., M. Daguchi, M. Seto, and T. Ariga, Northeastern Japan anomaly of the upper mantle, Sci. Rep. Tohoku Univ., Ser. V, 21, 19-35, 1971.

Kiminami, K., Sedimentary history of the late Cretaceous-Paleocene Nemuro Group, Hokkaido, Japan: A forearc basin of the Paleo-Kuril arctrench system, J. Geol. Soc. Japan, 89, 607-624, 1983.

Kiminami, K., M. Komatsu, K. Niida, and N. Kito, Tectonic divisions and stratigraphy of the Mesozoic rocks of Hokkaido, Japan, Monograph As soc. Geol. Collab., 31, 1-15, 1986 (in Japanese with English abstract).

Kimura, G., Tectonic evolution and stress field in the southwestern margin of the Kurile arc, J. Geol. Soc. Japan, 87, 757-768, 1981 (in Japanese with English abstract).

Kimura, G., Oblique subduction and collision: Forearc tectonics of the Kuril arc, Geology, 14, 404-407, 1986.

Marquis, G., A. G. Jones, and R. D. Hyndman, Coincident conductive and reflective middle to lower crust in southern British Columbia, Geophys. J. Int., 120, 111-131, 1995.

Matsunami, T. and F. Akita, Deep geothermal water resource and reservoir assessment of Konsen district, in eastern Hokkaido, Report of the geological survey of Hokkaido, 60, 119-156, 1989 (in Japanese with English abstract).

Miyakoshi, J., Electrical conductivity structure beneath the Japan Island Arc by geomagnetic induction study, J. Phys. Earth, 27, Suppl., S153S161, 1979

Mori, T., Conductivity anomalies in the eastern part of Hokkaido, Japan, Mem. Kakioka Mag. Obs., 16, 79-93, 1975.

Moriya, T., Seismo-tectonics of Hokkaido based on seismicity and focal mechanism studies, Monograph Assoc. Geol. Collab., 31, 475-485, 1986 (in Japanese with English abstract).

Moriziri, R., T. Hiroshima, Y. Murata, M. Makino, and M. Komazawa, Bouguer gravity anomalies in the eastern part of Hokkaido, Japan, Bull. Geol. Surv. Japan, 51, 537-558, 2000 (in Japanese with English abstract).

Niida, K. and N. Kito, Cretaceous arc-trench systems in Hokkaido, Monograph Assoc. Geol. Collab., 31, 379-402, 1986 (in Japanese with English abstract).

Nishida, Y., Conductivity structure in and around Hokkaido, Japan as revealed by the period dependence of the CA transfer functions, J. Geomag. Geoelectr., 34, 453-465, 1982.

Ogawa, Y., Two-dimensional resistivity modeling based on regional magnetotelluric survey in the Northern Tohoku district, Northeastern Japan, J. Geomag. Geoelectr., 39, 349-366, 1987.

Ogawa, Y. and T. Uchida, Two dimensional magnetotelluric inversion assuming Gaussian static shift, Geophys. J. Int., 126, 69-76, 1996.

Okubo, Y., Temperature analysis in the Earth's crust, in Handbook of Geophysical Exploration, Soc. Exploration Geophys. Jpn., 586-588, 1999 (in Japanese).

Research Group for Crustal Resistivity Structure, Resistivity distribution derived from ELF and VLF-MT measurements in the eastern part of Hokkaido, Japan*, Proc. 1984 Conductivity Anomaly Symp., 57-61, 1984 (in Japanese).

Rikitake, T. and Y. Honkura, Recent Japanese studies on conductivity anomalies, Phys. Earth Planet. Inter., 7, 203-212, 1973.

Saito, M., Automatic design of recursive digital filters, Buturi-Tansa (Geophys. Exploration), 31, 240-263, 1978 (in Japanese with Einglish abstract).

Sakakibara, S., K. Niida, H. Toda, N. Kito, G. Kimura, J. Tajika, T. Katoh, A. Yoshida, and Research Group of the Tokoro Belt, Nature and tectonic history of the Tokoro belt, Monograph Assoc. Geol. Collab., 31, 173187, 1986 (in Japanese with English abstract).

Sasai, Y., Spatial dependence of short-period geomagnetic fluctuations on Oshima Island (1), Bull. Earthq. Res. Inst., 45, 137-157, 1967.

Satoh, H. and S. Yamaguchi, 1:200,000 Geological map, Kushiro, Geological Survey of Japan, 1976.

Sen, P. N., P. A. Goode, and A. Sibbit, Electrical conduction in clay bearing sandstone at low and high salinities, J. Appl. Phys., 63, 4832-4840 
1988.

Shiozaki, I., Two-dimensional resistivity structure beneath Chugoku and Shikoku districts in Southwestern Honshu, Japan, Ph.D. Thesis, Kobe University, 276 pp., 1993 (in Japanese).

Shirozu, H., Introduction to clay mineralogy, Asakura-shoten, Tokyo, 185 pp., 1988 (in Japanese).

Suzuki, S., T. Sasatani, and Y. Motoya, Double seismic zone beneath the middle of Hokkaido, Japan, in the southwestern side of the Kurile arc, Tectonophys., 96, 59-76, 1983.

Swift, C. M., A magnetotelluric investigation of an electrical conductivity anomaly in the southwestern United States, Ph.D. Thesis., M.I.T., 211 pp., 1967.

Takakura, S., Resistivity of Neogene rocks in the Niigata and Akita oil fields, Japan, Buturi-Tansa (Geophys. Exploration), 48, 161-175, 1995 (in Japanese with English abstract).

Talwani, M., J. L. Worzel, and M. Landisman, Rapid gravity computation for two-dimensional bodies with application to the Mendocino submarine fracture zone, J. Geophys. Res., 64, 49-59, 1959.

Utada, H., Y. Hamano, and J. Segawa, Conductivity anomaly around the Japanese Islands, in Geology and Geophysics of the Japan Sea (JapanUSSR Monograph Series, Vol. 1), edited by N. Isezaki, I. I. Bersenev, K. Tamaki, B. Ya. Karp, and E. P. Lelikov, pp. 103-149, Terrapub, Tokyo,
1996

Uyeshima, M., Application of network MT method to the study of electrical conductivity structure in the eastern part of Hokkaido, Ph.D. Thesis, Univ. of Tokyo, 235 pp., 1990.

Uyeshima, M., H. Utada, and Y. Nishida, Network-MT method and its first results in central and eastern Hokkaido, NE Japan, Geophys. J. Int., 146, $1-19,2001$.

Wyllie, P. J., The Dynamic Earth, John Wiley, New York, 1971.

Yamaguchi, S., Y. Kobayashi, N. Oshiman, K. Tanimoto, H. Murakami, I. Shiozaki, M. Uyeshima, H. Utada, and N. Sumitomo, Preliminary report on regional resistivity variation inferred from the Network MT investigation in the Shikoku district, southwestern Japan, Earth Planets Space, 51, 193-203, 1999.

Yamamoto, A. and T. Moriya, Gravity anomalies and structure of Hokkaido*, Chikyu Monthly, 11, 377-385, 1989 (in Japanese).

${ }^{*}$ Titles are translated in English by the author H. S.

H. Satoh (e-mail: satoh@eos.hokudai.ac.jp), Y. Nishida, Y. Ogawa, M. Takada, and M. Uyeshima 